\title{
Study on the Connection of Courses between Higher Vocational Colleges and Applied Undergraduate Colleges
}

\author{
Li Zhiren \\ School of Political Science and Law, Baicheng Normal University, Baicheng, 137000, China \\ 494450117@qq.com
}

Keywords: Higher Vocational Colleges, Applied Undergraduate Colleges, Financial Management, Connection of Courses

\begin{abstract}
Under the new situation, the teaching work of higher vocational colleges and applied colleges should be improved and innovated effectively. In the actual teaching process, it is necessary to combine the curriculum content with the needs of the market industry, to promote the course convergence between higher vocational colleges and applied undergraduate colleges, how to make use of the development of market-oriented economy and the needs of industry posts. How to optimize and integrate teaching resources effectively and realize the connection of teaching courses are the problems that need to be paid attention to in the training of talents. Based on this, this paper takes the financial management specialty as an example to study the curriculum design and teaching work of higher vocational colleges and applied undergraduate colleges, and comprehensively analyzes the differences between them and the problems in the course convergence. The author also puts forward the corresponding improvement measures, hoping to enlighten the realization of the effective connection between higher vocational colleges and applied undergraduate courses.
\end{abstract}

\section{Introduction}

Under the current situation, with the rapid development of our country's economy and society, more and more strict demands are put forward to the employees in the market. The personnel of higher vocational education tend to pay attention to the education of professional and skilled talents, but with the upgrading and adjustment of industrial structure, the demand for all kinds of comprehensive talents is increasing. In order to effectively improve the connection effect between higher vocational colleges and applied undergraduate colleges in the training of talents, this paper studies the curriculum design of higher vocational colleges and applied undergraduate colleges. This paper analyzes the differences between the two and the problems in the course convergence, and puts forward the corresponding improvement measures, hoping to be helpful to the effective connection between the professional courses of higher vocational colleges and applied undergraduate colleges.

\section{The Value and Significance of the Connection between Higher Vocational Colleges and Applied Undergraduate Courses}

\subsection{It helps to promote the convergence of the two at the school level}

In the process of teaching in colleges and universities, we should pay attention to the cultivation of talents, especially the technical talents which are needed by the market and enterprises. To carry out talent education, it is necessary to start with the curriculum. The orientation of most higher vocational colleges and the training mode of practical talents are often influenced by many factors, and there are many differences. Generally speaking, there is no difference between the financial management teaching in higher vocational colleges and the financial management major in applied undergraduate courses, but the subjects responsible for the teaching and implementing are different. Therefore, there are many differences between the actual teaching objectives and the teaching contents used. In order to ensure the orderly development of personnel training policy, we should 
actively establish an integrated curriculum linking system, actively integrate and manage all teaching resources and teaching contents. In order to train talents, in addition to the training and education of students' professional knowledge, it is also necessary to cultivate and improve the students' ability to apply professional technology, so as to help students improve their ability to apply theoretical knowledge and practice professional technology. Effective completion of practical teaching objectives to ensure the orderly convergence of curriculum integration [1].

The combination of courses in higher vocational colleges and applied undergraduate courses can effectively improve the level of higher vocational education, and is more conducive to the cultivation of comprehensive financial management talents with higher quality and high technical application ability for the society.

\subsection{It is helpful to construct the channel for higher vocational students to enter undergraduate education}

Under the current situation, due to the continuous development of China's socialist market economy and the growing trend of economic globalization, there is a growing demand for comprehensive financial management personnel in society. The demands on the comprehensive quality and technical ability of the financial management personnel are also becoming higher and higher [2]. In view of this situation, in the teaching process of the higher vocational colleges, we should strengthen the teaching and comprehensive quality management of the financial management personnel. Improve the students' comprehensive quality and professional and technical level. For example, in the teaching of higher vocational students, it is necessary to conduct a comprehensive analysis of the students in higher vocational colleges, to grasp the actual learning situation of the students, and to effectively analyze the comprehensive situation of the students. The level of professional technology and the ability to master practical knowledge are still relatively weak. In view of this situation, it is necessary to strengthen the link with the curriculum of applied undergraduate courses, and strengthen the effective link with applied undergraduate education. Undergraduate education can improve the students' comprehensive quality, so as to better adapt to and meet the ever-changing market demand [3].

Therefore, in carrying out the education and training of talents in higher vocational colleges, we should strengthen the communication with applied undergraduate colleges, construct a reasonable three-dimensional channel for the cultivation of professional talents, so that students' study and practical knowledge application can be further taken one step further. In the process of personnel training in higher vocational colleges and applied undergraduate colleges, not only can the teaching resources of various teaching work be optimized and integrated, but also the actual teaching quality can be improved. At the same time, higher vocational students can feel the deeper level of teaching level and improve their comprehensive quality and professional management level.

\section{The Main Problems and Obstacles of Financial Management Major in Higher Vocational College and Applied Undergraduate College in the Process of Course Convergence}

\subsection{There are differences in the objectives and orientation of the two colleges and universities}

Under the current situation, the teaching work in higher vocational colleges is usually based on the market demand and the demand for professional talents, and its main teaching goal is to train the high technology and high quality talents needed by the market. To train and provide more suitable technical talents for the market industry and regional development in combination with the actual and industry needs of regional development. In the course of setting up specialized courses, it is often based on the market demand of the industry [4]. The purpose is to train more application-oriented talents, so it often shows obvious local, regional and industrial characteristics. Compared with higher vocational colleges, the orientation of applied undergraduate colleges is less obvious. The applied colleges and universities tend to pay more attention to scientific research, and pay less attention to the training of talents and scientific research. It does not give full play to the training strategy of professional and technical talents and high quality talents, mainly by means of 
the orientation of running a school, and does not give full play to the role and value of vocational education [5].

\subsection{There are differences in the training modes of talents between the two colleges and universities}

The purpose of talents training in higher vocational colleges is to take the employment of students as an important direction of teaching management, so the curriculum is usually based on the development of social needs and the actual needs of the industry. In the course design, most of them are specialized practice, as well as the form of cooperation between schools and enterprises and the combination of work and learning. The final curriculum design is based on the needs of the actual industry as a reference. And the actual job needs to be integrated into the curriculum and teaching process [6].

The teaching work of applied undergraduate colleges is to take the employment in the market and society as the direction of practical personnel training and teaching management, and to focus on the development of the subject in the course design. In the actual teaching process, the teaching method and the teaching mode are often relatively single, the classroom teaching often pays more attention to the students' theoretical knowledge teaching, neglects the students' actual professional technology cultivation and the knowledge application ability. It leads to the disconnection between the students' theoretical knowledge and the technical application ability, which leads to the students having sufficient theoretical knowledge and not having the relatively high quality technical application practical ability, which ultimately affects the students' actual employment development.

\subsection{There are differences in curriculum design and content arrangement between the two colleges and universities}

The talent training in higher vocational colleges is based on the needs of the market and the development of the industry. Therefore, in the course design, more attention is paid to the teaching of practical courses, It is often based on the actual demand of the job as the basis of the curriculum, and the actual teaching content is also more biased towards the industry requirements and actual business processes, in this kind of teaching model and curriculum, Learning can effectively master a wealth of theoretical and professional knowledge, at the same time can combine with the needs of the job, more in line with the position of the application of practice, to ensure the quality of their own business technology continues to improve [7].

Due to the differences between their own orientation and higher vocational colleges, the applied undergraduate colleges often pay more attention to the arrangement of the theoretical and practical scientific research on their specialty courses. In the actual teaching process, it often pays more attention to the explanation and teaching of professional knowledge, neglects the application of students' professional knowledge and the practice of professional technology. As a result, students' technical level is difficult to improve, and professional theoretical knowledge is becoming more and more abundant.

\section{Measures to Promote the Effective Connection of Financial Management Courses between Higher Vocational Colleges and Applied Universities}

\subsection{Jointly set the training goal of professional talents}

In order to ensure and improve the quality and level of the linking courses between higher vocational colleges and applied undergraduate colleges, it is necessary to effectively combine course teaching to carry out curriculum design. Therefore, it is necessary to set up the courses of higher vocational colleges and applied colleges based on the same teaching, so as to effectively improve the linking effect of the two courses in teaching [8]. At present, the teaching of financial management in higher vocational colleges often pays more attention to the post relationship with the small and medium-sized enterprises in the region. In teaching, the purpose of teaching is to train small and medium-sized enterprises with financial budget and analysis. Accounting, auditing, tax 
processing and other related technical and quality financial management personnel. Under this kind of teaching goal, the course arrangement should pay attention to the comprehensive teaching guidance to the students' specialty, and ensure that the students' professional quality and technology application meet the needs of the enterprise. In view of the applied undergraduate finance teaching, we should pay attention to the improvement of teaching quality and teaching level in the actual teaching content and teaching mode. Let students feel the importance of teaching in the course of their study. The curriculum should also organize and set up a higher level of professional courses to train students with higher quality of financial knowledge. To enable students to be competent in many areas of finance, such as financial management and portfolio investment, and to effectively carry out professional work. Its main positions include corporate accounting analyst (CFA), Chief Financial Officer (CFO) and financial planner (CFP) and so on.

\subsection{Work together to plan and select professional career orientations}

In view of talent training teaching in higher vocational colleges, vocational teaching should be carried out in combination with the actual financial management specialty. In the aspect of teaching management, the teaching direction of higher vocational colleges is not different from that of applied undergraduate courses. The only difference is that the following students have different employment orientation due to the differences in the level of teaching management. Therefore, in the training of professional talents, higher vocational colleges and applied undergraduate colleges should plan and set together. This needs to be effectively combined with the needs of the market to set up, can be social enterprises and institutions of financial management posts, state financial management posts; Social intermediary agencies related to financial advice, financial management and tax planning and other positions to take into account to ensure that the teaching plan meets the requirements.

Generally speaking, in the employment of students majoring in financial management in higher vocational colleges, the following requirements should be met: ability of financial budget and analysis, ability of tax processing, ability of accounting and accounting, Ability to write and express related positions and the ability to operate and use related software. These abilities are closely related to the actual financial management, and the financial management staff must have these basic and more important skills. The talent training of applied undergraduate colleges often needs to have a higher quality of knowledge and professional practical ability, need to carry out financial advice and planning, The capital operation and value orientation of the enterprise as well as the investment and financing decision of the enterprise bring into play its own financial management ability and the practical ability of the application of knowledge.

\subsection{Focus on the fuse of courses and certificates}

Both the training and education of applied undergraduate talents in higher vocational colleges require students to master the knowledge of basic financial management courses and the level of theory and practice. It also needs to combine with the actual position to obtain the relevant vocational skill certificate in the field of financial management, which is more beneficial for the students themselves to study and obtain employment in the future. In the teaching of financial management, we should pay attention to the integration of curriculum and vocational skill certificate, which not only requires students to master the basic knowledge of financial management theory and the practical ability of applying knowledge, but also needs to effectively combine the needs of actual professional posts. To develop towards more professional and comprehensive talents to ensure that students have a more favorable foundation in the application of subsequent skills and knowledge application.

\section{Conclusion}

In general, under the current situation, it is helpful for higher vocational students to accept higher level and higher level professional education by effectively linking the courses of financial management major between higher vocational colleges and applied undergraduate colleges. In order 
to achieve comprehensive talent training needs and goals. In order to effectively improve the connection effect between higher vocational colleges and applied undergraduate colleges in personnel training. In view of the differences in the objectives and orientation of running a school, the difference in the training mode of talents, and the differences in curriculum design and content arrangement between higher vocational colleges and applied undergraduate colleges, the author points out that there are some differences in the teaching objectives and the orientation of the courses. We should actively adopt the strategies of jointly setting the training goal of professional talents and jointly planning and choosing the professional career orientation and paying attention to the curriculum design and convergence of the course certificate. Continuous provision of higher vocational colleges and applied-oriented undergraduate courses linking effect and quality.

\section{Acknowledgements}

In this paper, the research was sponsored by the Reform of Vocational Education and Adult Education Foundation in the Education Department of Jilin Province in 2018(Project No. 2018ZCY113).

\section{References}

[1] ZHU Lisa, HENG Shuzhen. Study on the Teaching Problems of the Linking up of Higher Mathematics Courses in Applied Undergraduate Colleges [J]. Journal of Jilin Teachers Institute of Engineering and Technology, 2018, 34(08):10-12.

[2] GUO Zhanghua, XIAO Xuefeng. Discussion on the Connection between the Courses of Traditional Chinese Medicine Specialty in Higher Vocational Colleges and Applied Undergraduate Colleges [J]. Guangdong Vocational Technical Education and Research, 2015(03):28-31.

[3] ZHANG Guofu. Research on the Connection between Higher Vocational Colleges of Civil Engineering and Applied Undergraduate Course System [J]. Education Modernization, 2018, 5(25):95-96.

[4] KONG Fengqin. Research and practice on the Connection between Higher Vocational Education and Applied Undergraduate Course System [J]. Cultural and Educational Materials, 2018(08): 165-167+188.

[5] HUANG Qiyan. Problems and Countermeasures of Linking Higher Vocational Colleges with Applied Undergraduate Courses: A Case Study of Chinese Major in Shantou Vocational and Technical College [J]. Journal of Southern Vocational Education, 2018, 8(01):23-29+96.

[6] CHEN Lijia. Study on the Connection of Courses between Higher Vocational Colleges and Applied Universities: A Case Study of Financial Management Specialty [J]. Modern Business Trade Industry, 2016, 37(31):162-163.

[7] LONG Pingfeng, XIAO Qingfeng. Study on the Connection of Public Basic Courses between Higher Vocational Colleges and Applied Undergraduate Colleges [J]. Education Teaching Forum, 2016(44):3-4.

[8] LONG Pingfeng, XIAO Qingfeng. Study on the Connection of Technology Applied Undergraduate Education Courses in Higher Vocational Colleges and Applied Undergraduate Colleges [J]. The Guide of Science \& Education, 2016(09):19-20. 